06.1

\title{
Механические свойства композитного покрытия SiC на графите, полученного методом замещения атомов
}

\author{
() А.С. Гращенко ${ }^{1}$, С.А. Кукушкин ${ }^{2, \uparrow, ~ А . В . ~ О с и п о в ~}{ }^{1}$, А.В. Редьков ${ }^{1}$ \\ ${ }^{1}$ Институт проблем машиноведения РАН, Санкт-Петербург, Россия \\ ${ }^{2}$ Санкт-Петербургский политехнический университет Петра Великого, Санкт-Петербург, Россия \\ 『 E-mail: sergey.a.kukushkin@gmail.com
}

Поступило в Редакцию 11 июня 2021 г.

В окончательной редакции 11 июня 2021 r.

Принято к публикации 1 июля 2021 r.

\begin{abstract}
Впервые исследуются механические свойства композитных покрытий из карбида кремния на графите, нанесенных новым методом отжига исходного графита в контакте с расплавом кремния в атмосфере монооксида углерода. Образцы изучены методами наноиндентирования и растровой электронной микроскопии. Показано, что формируемое покрытие состоит из сплошной пленки монокристаллического карбида кремния, лежащей на поверхности, дендритов и кристаллических друз, корнями уходящих в глубь образца через систему пор. Показано, что покрытие значительно повышает механические характеристики поверхности графита, в том числе микротвердость.
\end{abstract}

Ключевые слова: карбид кремния, графит, покрытие, метод замещения атомов.

DOI: 10.21883/PJTF.2021.20.51605.18918

В настоящее время графитовые изделия широко используются в различных областях технологии и промышленности (от деталей высокотемпературных печей до атомных реакторов) и при использовании подвергаются различным нагрузкам: механическим, химическим, тепловым. Для защиты графита от подобных воздействий на него часто наносят различные защитные покрытия [1], начиная от ниобия [2], оксидов [3], нитридов [4] и заканчивая различными композитными слоями [5]. В частности, одним из перспективных покрытий является карбид кремния [6], обладающий химической стойкостью, высокой твердостью и теплопроводностью. Ранее авторами был предложен метод нанесения карбидкремниевых покрытий на графит [7] путем отжига графитового изделия в контакте с расплавом $\mathrm{Si}$ в атмосфере моноксида углерода (CO). Метод основан на реакции взаимодействия $\mathrm{CO}$ и кремния с образованием $\mathrm{SiC}$, подробно исследованной авторами при росте тонких пленок $\mathrm{SiC}$ на подложках кремния [8-10]. Было показано, что этот метод позволяет выращивать толстые (до $1 \mathrm{~mm}$ ) покрытия $\mathrm{SiC}$ на графите. Настоящая работа посвящена исследованию микротвердости и структуры композитных покрытий $\mathrm{SiC}$, нанесенных на поверхность графита указанным методом.

Для проведения экспериментов был использован графитовый образец марки МПГ-7, на который сверху была установлена пластина кремния толщиной $300 \mu \mathrm{m}$ и площадью порядка $1 \mathrm{~cm}^{2}$. Конструкция отжигалась в вакуумной печи в атмосфере $\mathrm{CO}$ с добавлением силана при температуре $1450^{\circ} \mathrm{C}$ и общем давлении 0.5 Torr в течение $20 \mathrm{~min}$. После процесса синтеза полученные образцы покрытий $\mathrm{SiC}$ изучались методом растровой электронной микроскопии (РЭМ) на микроскопе Tescan
Mira 3. Механические свойства поверхности были изучены с использованием установки для наноиндентирования Nanotest 600.

РЭМ-изображения поверхности и скола образца показаны на рис. $1, a$ и $b$ соответственно. Из рис. $1, a$ видно, что покрытие представляет собой сплошной кристаллический слой, на котором есть области с различным контрастом. Детальное изучение поверхности после механического отделения пленки $\mathrm{SiC}$ позволяет заключить, что под темными областями наблюдаются пустоты (см. вставку на рис. $1, a)$. Поры также видны на сколе образца (рис. $1, b)$. Из рис. $1, b$ видно, что непосредственно поверхностный слой $\mathrm{SiC}$ является сплошным и имеет толщину порядка нескольких микрометров. На больших глубинах от поверхности формируется смешанная структура из пор, кристаллов и друз из карбида кремния с включениями графита, и на глубинах порядка нескольких сотен микрометров объемная доля $\mathrm{SiC}$ постепенно приближается к нулю. Проникновение карбида кремния на такие глубины обусловлено довольно большой пористостью исходной матрицы графита и тем фактом, что затекший в поры расплав кремния при взаимодействии с $\mathrm{CO}$ превращается в $\mathrm{SiC}$, который имеет в 2 раза меньший объем кристаллической ячейки, чем сам кремний [11]. В результате при формировании $\mathrm{SiC}$ появляются новые пустоты, и каналы в графите не „закупориваются“, а остаются открытыми для дальнейшего проникновения расплава кремния вглубь. В результате в объеме графита формируются „корни“ из $\mathrm{SiC}$, прочно связывающие верхнюю монокристаллическую пленку $\mathrm{SiC}$ с графитовой матрицей. На РЭМ-изображениях областей в объеме кристалла (рис. 2,a) на глубине порядка $150 \mu \mathrm{m}$ видны различные формы образующих- 

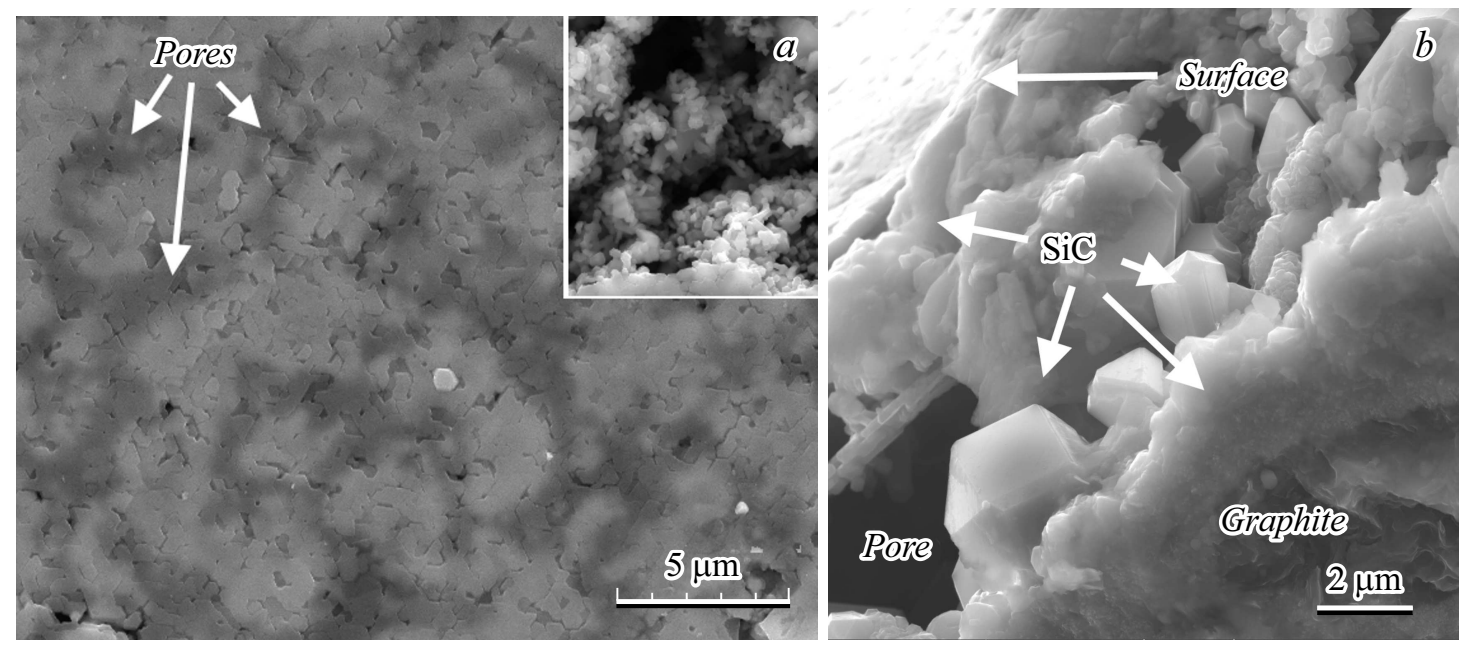

Рис. 1. РЭМ-изображения поверхности $(a)$ и скола $(b)$ образца композитного покрытия $\mathrm{SiC}$ на поверхности графита. Темные области на части $a$ соответствуют порам под поверхностью пленки $\mathrm{SiC}$. На вставке (часть $a$ ) показана внутренняя поверхность поры после снятия пленки $\mathrm{SiC}$.
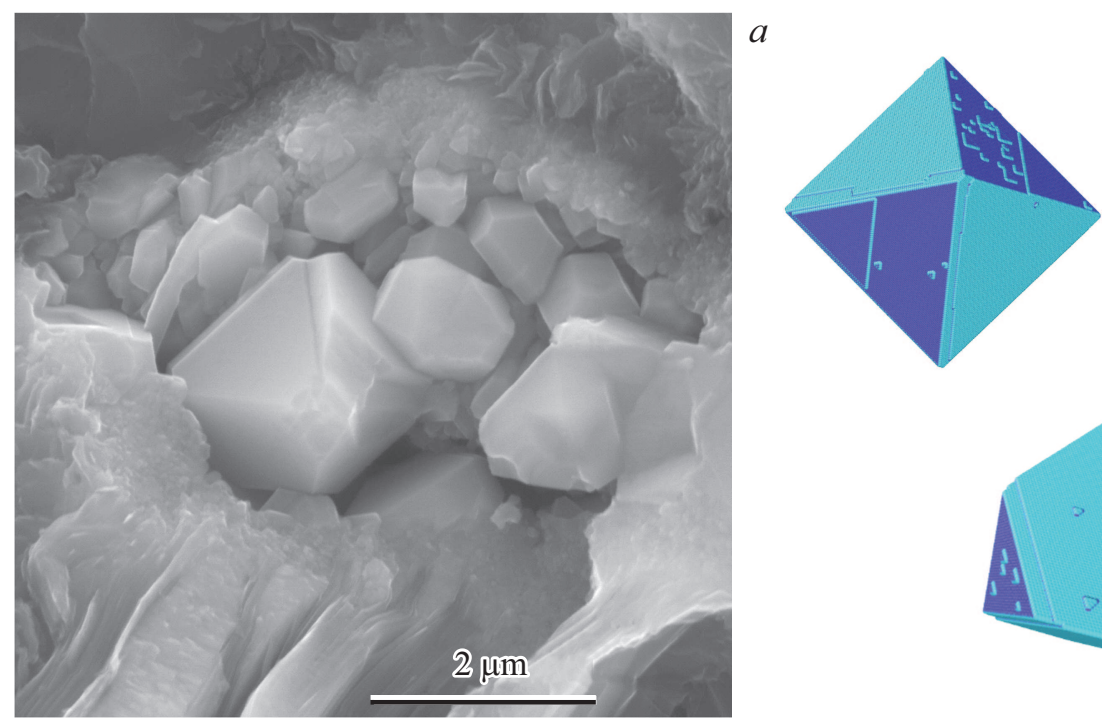

$b$

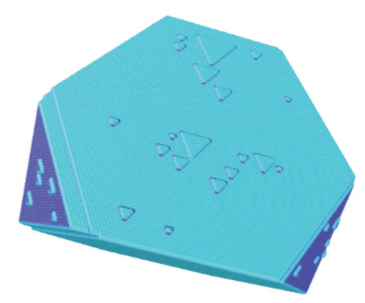

Рис. 2. РЭМ-изображение кристаллов $\mathrm{SiC}$, наблюдаемых в порах в матрице углерода (a), и ростовые формы кубического $\mathrm{SiC}$, полученные с помощью моделирования методом Монте-Карло в пакете CrystalGrower [12] при различных соотношениях компонентов $\mathrm{Si}$ и $\mathrm{C}$ в процессе роста $(b)$.

ся микрокристаллов $\mathrm{SiC}$, соответствующие кубическому политипу карбида кремния. Отметим, что проведенное в настоящей работе моделирование процесса формирования кристаллов $\mathrm{SiC}$ кубического политипа методом Монте-Карло в пакете CrystalGrower [12,13] при различных соотношениях компонентов $\mathrm{Si}$ и C дает спектр форм кристаллов, действительно наблюдающихся в эксперименте (рис. 2, $b$ ). Так, кристаллы правильной октаэдрической формы наблюдаются при формировании кристалла из смеси стехиометрического состава, тогда как при избытке углерода в системе наблюдаются кристаллические формы со „скошенными“ гранями.

Микротвердость покрытия измерялась с помощью наноиндентора при максимальной силе вдавливания
$1 \mathrm{mN}$. Нагрузка и разгрузка индентора осуществлялись со скоростью 0.5 и $1 \mathrm{mN} / \mathrm{s}$ соответственно. Отметим, что вследствие наличия пористых областей под поверхностью тонкого монокристаллического слоя $\mathrm{SiC}$ (рис. 1) в некоторых случаях увеличение силы вдавливания приводило к появлению крупных скачков деформации (до нескольких сотен нанометров) на кривых наноиндентирования (см. штриховую кривую 3 на рис. $3, a$ ). Такие скачки, вызванные наличием пор, при анализе экспериментальных данных существенно искажают результат. Отметим, что скачки деформации регистрировались и при наноиндентировании до $1 \mathrm{mN}$, но это происходило значительно реже. Для определения твердости модифицированного и исходного графита отбирались 

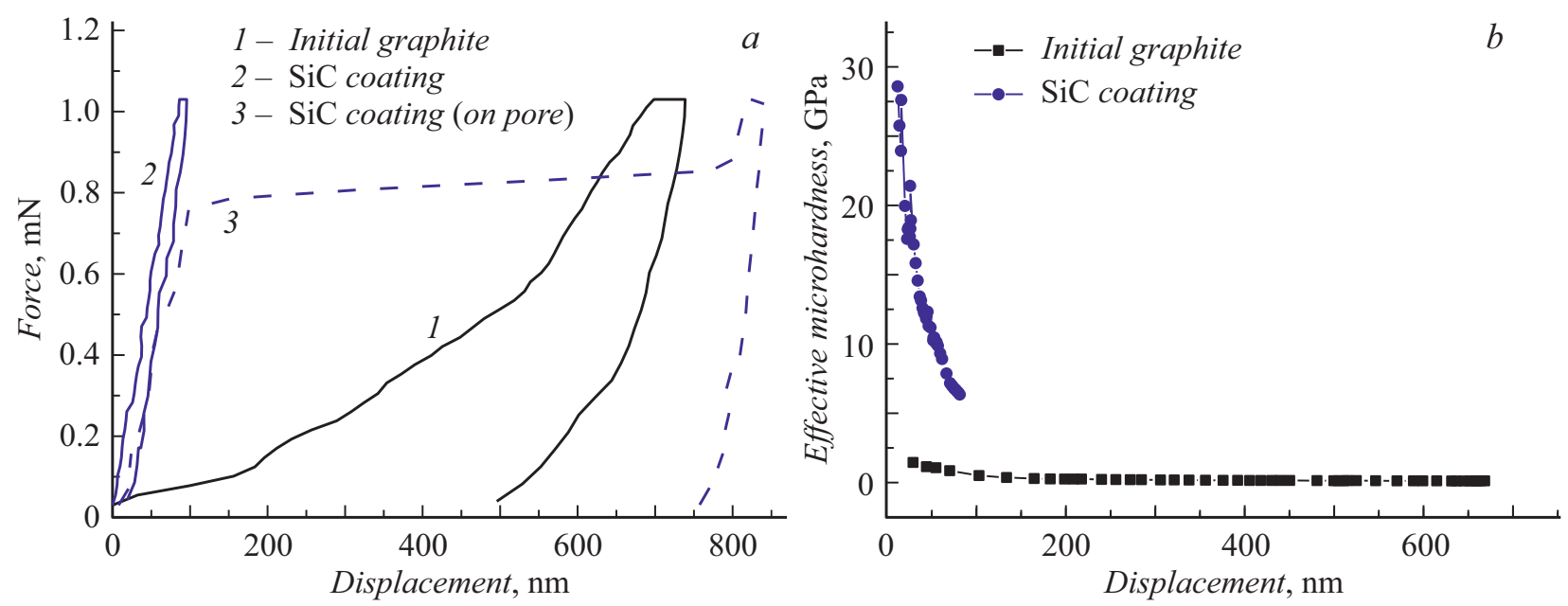

Pис. 3. $a-$ кривые нагрузки-разгрузки исходного графита (1), а также сформированного покрытия в двух областях: лежащего непосредственно на графите (2) и „висящего“ над порой (3). $b$ - зависимость эффективной твердости материалов от глубины.

кривые наноиндентирования исключительно без скачков деформации. Типичные зависимости силы вдавливания от глубины проникновения индентора в исследуемый материал для исходной и модифицированной областей графита представлены сплошными кривыми 1 и 2 на рис. 3,a. Рассчитанные по стандартной методике [14] зависимости микротвердости от глубины представлены на рис. $3, b$. Видно, что покрытие из $\mathrm{SiC}$ существенно повышает твердость поверхности до величины 25-28 GPa, тогда как твердость исходного графита составляет 100-130 MPa.

Таким образом, в работе показано, что отжиг графита в контакте с расплавом кремния в атмосфере СО позволяет сформировать защитное покрытие из карбида кремния, представляющее собой сплошную пленку на поверхности, и разветвленную систему кристаллов и кристаллических друз, уходящую на большую глубину. Покрытие существенно повышает твердость и механическую стойкость материала и обладает антиокислительными свойствами, защищая поверхность графитового изделия от различных воздействий.

\section{Благодарности}

Исследования проводились с использованием оборудования УНУ „Физика, химия и механика кристаллов и тонких пленок“ ИПМаш РАН, Санкт-Петербург). Авторы выражают благодарность демонстрационной лаборатории ООО „Тескан“ за содействие в электронномикроскопических исследованиях.

\section{Финансирование работы}

Исследования выполнены при финансовой поддержке Минобрнауки России в рамках реализации программы Научного центра мирового уровня по направлению „Пе- редовые цифровые технологии“ СПбПУ (соглашение № 075-15-2020-934 от 17.11.2020 г.).

\section{Конфликт интересов}

Авторы заявляют, что у них нет конфликта интересов.

\section{Список литературы}

[1] J.M. Criscione, R.A. Mercuri, E.P. Schram, A.W. Smith, H.F. Volk, High temperature protective coatings for graphite (Union Carbide Corp., Parma, OH, 1964).

[2] J.W. Koger, C.E. Holcombe, J.G. Banker, Thin Solid Films, 39, 297 (1976). DOI: 10.1016/0040-6090(76)90649-0

[3] L. Constantin, L. Fan, Q. Zou, B. Thomas, J. Roger, J.-M. Heintz, C. Debiemme-Chouvy, B. Mortainge, Y.F. Lu, J.-F. Silvain, Carbon, 158, 607 (2020). DOI: $10.1016 /$ j.carbon.2019.11.032

[4] Y.-J. Cho, A. Summerfield, A. Davies, T.S. Cheng, E.F. Smith, C.J. Mellor, A.N. Khlobystov, C.T. Foxon, L. Eaves, P.H. Beton, S.V. Novikov, Sci. Rep., 6 (1), 34474 (2016). DOI: $10.1038 /$ srep34474

[5] X. Ren, W. Wang, T. Shang, H. Mo, P. Feng, L. Guo, Z. Li, Composites B, 161, 220 (2019). DOI: 10.1016/j.compositesb.2018.10.080

[6] S.A. Khalife Soltani, M. Azadbeh, Adv. Compos. Mater. (Published online: 2 Dec 2020). DOI: $10.1080 / 09243046.2020 .1850399$

[7] A.S. Grashchenko, S.A. Kukushkin, A.V. Osipov, A.V. Redkov, N.A. Feoktistov, Article from graphite with modified nearsurface layer and method of modification of article surface, having base from graphite, patent № RU 2695423 (26.02.2018).

[8] С.А. Кукушкин, А.В. Осипов, ФТТ, 50 (7), 1188 (2008). [S.A. Kukushkin, A.V. Osipov, Phys. Solid State, 50 (7), 1238 (2008). DOI: 10.1134/S1063783408070081].

[9] S.A. Kukushkin, A.V. Osipov, J. Phys. D: Appl. Phys., 47 (31), 313001 (2014). DOI: 10.1088/0022-3727/47/31/313001 
[10] V.V. Kidalov, S.A. Kukushkin, A.V. Osipov, A.V. Redkov, A.S. Grashchenko, I.P. Soshnikov, M.E. Boiko, M.D. Sharkov, A.F. Dyadenchuk, Mater. Phys. Mech., 36 (1), 39 (2018). DOI: 10.18720/MPM.3612018_4

[11] А.В. Редьков, А.С. Гращенко, С.А. Кукушкин, А.В. Осипов, К.П. Котляр, А.И. Лихачев, А.В. Нащекин, И.П. Сошников, ФТТ, 61 (3), 433 (2019). DOI: 10.21883/FTT.2019.03.47232.265 [A.V. Redkov, A.S. Grashchenko, S.A. Kukushkin, A.V. Osipov, K.P. Kotlyar, A.I. Likhachev, A.V. Nashchekin, I.P. Soshnikov, Phys. Solid State, 61 (3), 299 (2019). DOI: $10.1134 / \mathrm{S} 1063783419030272]$.

[12] M.W. Anderson, J.T. Gebbie-Rayet, A.R. Hill, N. Farida, M.P. Attfield, P. Cubillas, V.A. Blatov, D.M. Proserpio, D. Akporiaye, B. Arstad, Nature, 544, 456 (2017).

DOI: $10.1038 /$ nature21684

[13] A. Stukowski, Model. Simul. Mater. Sci. Eng., 18 (1), 015012 (2010). DOI: 10.1088/0965-0393/18/1/015012

[14] A.C. Fischer-Cripps, D.W. Nicholson, Appl. Mech. Rev., 57 (2), B12 (2004). DOI: 10.1115/1.1704625 